\title{
КОМПЛЕКСООБРАЗОВАНИЕ ПЕРЕХОДНЫХ МЕТАЛЛОВ С 8-ОКСИХИНОЛИНОМ, ХИМИЧЕСКИ ЗАКРЕПЛЕННЫМ НА ПОВЕРХНОСТИ КОМПОЗИТА СИЛИКАГЕЛЬ-ПОЛИАНИЛИН
}

\author{
(С) 2013 г. Е. В. Рябченко*, Э. С. Яновская*, В. А. Тертых $* *$, О. Ю. Кичкирук*** \\ * Киевский национальный университет им. Тараса Шевченко, Украина \\ ** Институт химии поверхности им. А.А. Чуйко НАН Украины, Киев \\ ***Житомирский государственный университет им. И. Франко, Украина \\ E-mail: katya-ryabchenko@yandex.ru \\ Поступила в редакцию 24.01.2012 г.
}

\begin{abstract}
Исследованы комплексообразующие свойства композита силикагель-полианилин с ковалентно закрепленным посредством реакции Манниха 8-оксихинолином по отношению к ионам $\mathrm{Pb}(\mathrm{II})$, $\mathrm{Cd}(\mathrm{II}), \mathrm{Cu}(\mathrm{II}), \mathrm{Ni}(\mathrm{II}), \mathrm{Co}(\mathrm{II}), \mathrm{Al}(\mathrm{III}), \mathrm{Fe}(\mathrm{III})$ и Мo(VI). Полученный адсорбент имеет высокую сорбционную емкость и удовлетворительные кинетические характеристики, что позволяет использовать его для выделения или предконцентрирования ионов переходных металлов. Из анализа электронных спектров диффузного отражения и соответствующих изотерм адсорбции получены данные о составе и строении комплексов исследованных металлов с иммобилизованным на поверхности композита 8-оксихинолином.
\end{abstract}

DOI: $10.7868 / \mathrm{S} 0044457 \mathrm{X} 1303015 \mathrm{X}$

Композиционные материалы на основе неорганических оксидов и полианилина отличаются простотой синтеза, относительно низкой себестоимостью, интересными полифункциональными свойствами $[1,2]$. Благодаря этим особенностям такие композиционные материалы могут применяться для создания чувствительных сенсоров [3], катализаторов [4], антикоррозиционных покрытий [5], стационарных фаз для хроматографии и адсорбентов [6]. Ранее нами было установлено, что полианилин (ПАн), in situ иммобилизованный на поверхности частиц природных минералов разной химической природы (украинской сапонитовой глины, карельского шунгита и сокирницкого клиноптилолита) и кремнеземов, является хорошим ионообменником, за счет чего проявляет высокую адсорбционную активность по отношению к анионам неметаллов и поливалентных металлов, например $\mathrm{Cr}(\mathrm{VI})$, Mo(VI), $\mathrm{W}(\mathrm{VI}), \mathrm{P}(\mathrm{V})$ и $\mathrm{As}(\mathrm{V})$ [7-9]. Вместе с тем комплексообразующие свойства in situ модифицированного полианилином силикагеля по отношению $\mathrm{K}$ катионам переходных металлов выражены значительно слабее [10]. Однако наличие групп - NHв иммобилизованном полианилине можно использовать для закрепления на поверхности композита реагентов, обладающих выраженными комплексообразующими свойствами, например оксина. Для этой цели можно применить реакцию аминометилирования. Реакция Манниха с успехом использовалась ранее для иммобилизации ряда соединений с подвижным атомом водорода, в том числе и реагентов фенольного типа [11].

В настоящей работе осуществлен синтез композита силикагель-Полианилин (СГ-ПАн) с иммобилизованным с помощью реакции аминометилирования 8-оксихинолином и изучены процессы комплексообразования полученного адсорбента по отношению к катионам переходных металлов.

\section{ЭКСПЕРИМЕНТАЛЬНАЯ ЧАСТЬ}

Композит с иммобилизованным 8-оксихинолином получали в две стадии. На первой стадии путем окислительной полимеризации анилина пероксодисульфатом аммония в $1.2 \mathrm{M}$ соляной кислоте на протяжении суток осуществляли in situ модификацию силикагеля полианилином аналогично [10]. В качестве носителя использовали силикагель с удельной поверхностью 256 м²$^{2}$ г и диаметром частиц $0.1-0.2$ мм. Согласно данным [12, 13], при избранных условиях синтеза и соотношениях концентраций реагентов полианилин на поверхности кремнезема фиксируется в виде эмеральдинового основания.

На второй стадии проводили химическое закрепление 8-оксихинолина на поверхности композита СГ-ПАн с помощью реакции Манниха, 
используя в качестве метилирующего реагента параформальдегид [14, 15]. Для синтеза 8-оксихинолин брали из расчета 0.5 ммоль на каждый грамм СГ-ПАн. Схематическое строение поверхностного слоя полученного адсорбента и его разнолигандного комплекса с ионами $\mathrm{Cu}(\mathrm{II})$ представлено ниже по тексту.

Исходные растворы металлов готовили растворением точных навесок следующих солей (ч.д.а.): $\mathrm{ZnCl}_{2}, \mathrm{~Pb}\left(\mathrm{NO}_{3}\right)_{2}, \mathrm{CuCl}_{2} \cdot 2 \mathrm{H}_{2} \mathrm{O}, \mathrm{Cd}\left(\mathrm{NO}_{3}\right)_{2} \cdot 4 \mathrm{H}_{2} \mathrm{O}$, $\mathrm{NiCl}_{2} \cdot 6 \mathrm{H}_{2} \mathrm{O}, \mathrm{FeCl}_{3} \cdot 6 \mathrm{H}_{2} \mathrm{O}, \mathrm{Co}\left(\mathrm{NO}_{3}\right)_{2} \cdot 6 \mathrm{H}_{2} \mathrm{O}$, $\mathrm{Al}\left(\mathrm{NO}_{3}\right)_{3}$ и $\left(\mathrm{NH}_{4}\right)_{6} \mathrm{Mo}_{7} \mathrm{O}_{24} \cdot 4 \mathrm{H}_{2} \mathrm{O}$ с подкислением растворов соответствующими кислотами во избежание гидролиза. Концентрации металлов в исходных растворах уточняли титриметрически. Рабочие растворы нужной концентрации готовили разбавлением исходных растворов бидистиллированной водой.

Процессы адсорбции изучали в статическом режиме с массой сорбента 0.1 г и объемом рабочих растворов $25 \mathrm{~cm}^{3}$. $\mathrm{pH}$ рабочих растворов поддерживали добавлением соответствующих буферов, приготовленных из фиксаналов стандартных растворов или аммиачно-ацетатных смесей, и контролировали на иономере И-130 2М.1.

Равновесную концентрацию металлов определяли фотометрически на спектрофотометре СФ-46 с использованием квадратных кювет длиной 1 см согласно следующим методикам: $\mathrm{Pb}(\mathrm{II}), \mathrm{Cd}(\mathrm{II})$, $\mathrm{Co}(\mathrm{II})$ и $\mathrm{Cu}(\mathrm{II})$ - с 4-(2-пиридилазо)резорцином при длинах волн $\lambda$, равных 520, 500, 510 и 490 нм соответственно [16]. Для фотометрического определения концентрации цинка(II) в равновесных растворах использовали методику с мурексидом при $\lambda=455$ нм, для $\mathrm{Fe}(\mathrm{III})-$ реакцию с фенантролином в присутствии восстановителя [14], для $\mathrm{Ni}(\mathrm{II})$ - реакцию с диметилглиоксимом, а для Mo(VI) - с аскорбиновой кислотой в серной кислоте и роданидом калия при $\lambda=470$ нм [16]. Количество адсорбированного металла определяли по разности между содержанием ионов в исходном и равновесном растворах.

Электронные спектры диффузного отражения (ЭСДО) комплексов на поверхности модифицированного силикагеля регистрировали на прибоpe Specord M40. ИК-спектры регистрировали на спектрофотометре Nexus 470 с Фурье-преобразованием.

\section{РЕЗУЛЬТАТЫ И ИХ ОБСУЖДЕНИЕ}

Для подтверждения ковалентной иммобилизации 8-оксихинолина на поверхности СГ-ПАн сравнивали ИК-спектры синтезированного адсорбента, композита СГ-ПАн и 8-оксихинолина. В ИК-спектре полученного адсорбента в областях ниже 1250 и выше $3600 \mathrm{~cm}^{-1}$ наблюдаются интенсивные полосы поглощения остова и гидратного покрова кремнезема, что затрудняет идентификацию некоторых функциональных групп иммобилизованного оксина. Вместе с тем новую полосу $v(\mathrm{C}-\mathrm{H})$ в области $3000 \mathrm{~cm}^{-1}$ в спектре адсорбента можно идентифицировать достаточно надежно. Наиболее информативной для подтверждения присутствия оксина в модифицирующем слое является область 1000-1700 $\mathrm{cm}^{-1}$. По сравнению с композитом СГ-ПАн в спектре полученного адсорбента можно отметить усиление интенсивности полос поглощения при 1380, 1440 и $1470 \mathrm{~cm}^{-1}$, которые отвечают скелетным колебаниям ароматических колец. Кроме того, при 1635 см$^{-1}$ проявляется интенсивная полоса поглощения, характерная для $v(\mathrm{C}=\mathrm{N})$ и $\delta(\mathrm{O}-\mathrm{H})$ молекул 8-оксихинолина. Наличие в спектре адсорбента серии полос в области 1380-1470 $\mathrm{cm}^{-1}$, отвечающих скелетным колебаниям группы $-\mathrm{CH}_{2}-\mathrm{N}=[17]$, подтверждает закрепление 8-оксихинолина по NH- группам нанесенного на силикагель полианилина.

По данным компьютерной обработки ТГ-кривых композита СГ-ПАн и адсорбента с иммобилизованным оксином, концентрация связавшегося с поверхностью 8-оксихинолина составляет 0.32 ммоль/г. С учетом концентрации реагента, первоначально взятого для иммобилизации, выход реакции аминометилирования составляет $63 \%$.

Поскольку перед адсорбцией к рабочим растворам солей металлов добавляли стандартные буферные растворы различной химической природы, в исходных растворах формировались координационные сферы металлов, в которых, в зависимости от состава буфера, доминировали аква-, амино-, цитратные, хлоридные или другие лиганды (табл. 1). При этом адсорбция осуществлялась за счет вхождения привитых молекул 8-оксихинолина в первичные координационные сферы металлов с образованием на поверхности разнолигандных комплексов.

Зависимость степени извлечения ионов исследованных металлов композитом СГ-ПАн с химически привитым 8-оксихинолином от рН и химического состава исходной среды показана в табл. 1 и 2. Как следует из этих таблиц, полученный адсорбент, в отличие от исходного композиционного материала, проявляет высокую адсорбционную активность по отношению к микроколичествам катионов переходных металлов, количественно извлекая ионы $\mathrm{Al}(\mathrm{III})$ и $\mathrm{Fe}(\mathrm{III})$ в слабокислотной области и более чем на 95\% сорбируя ионы $\mathrm{Cu}(\mathrm{II})$, $\mathrm{Cd}(\mathrm{II}), \mathrm{Pb}(\mathrm{II})$ и $\mathrm{Mo}(\mathrm{VI})$ в кислой и слабокислой среде. 
Таблица 1. Максимальные значения степени сорбции (\%) ионов металлов композитом СГ-ПАн с привитым 8оксихинолином в зависимости от рН и химического состава буферного раствора. Условия эксперимента: статический режим, масса адсорбента 0.1 г, масса металла в исходном растворе 100 мкг, время адсорбции 24 ч

\begin{tabular}{|c|c|c|c|c|}
\hline $\begin{array}{c}\text { Ион } \\
\text { металла }\end{array}$ & pH среды & Химический состав буфера & \begin{tabular}{|} 
Доминирующие комплексы ме- \\
таллов в исходных растворах
\end{tabular} & $\begin{array}{c}\text { Степень сорбции, } \\
\%\end{array}$ \\
\hline $\mathrm{Zn}(\mathrm{II})$ & 6.8 & $\mathrm{KH}_{2} \mathrm{PO}_{4}$ и $\mathrm{Na}_{2} \mathrm{HPO}_{4}$ (фосфатный) & {$\left[\mathrm{Zn}\left(\mathrm{HPO}_{4}\right)_{4}\right]^{6-}$} & 66.25 \\
\hline $\mathrm{Al}(\mathrm{III})$ & 6.8 & $\mathrm{KH}_{2} \mathrm{PO}_{4}$ и $\mathrm{Na}_{2} \mathrm{HPO}_{4}$ (фосфатный) & {$\left[\mathrm{Al}\left(\mathrm{H}_{2} \mathrm{O}\right)_{6}\right]^{3+}$} & 99.99 \\
\hline $\mathrm{Fe}(\mathrm{III})$ & $\begin{array}{l}4.0 \\
6.8\end{array}$ & $\begin{array}{l}\mathrm{K}_{2} \mathrm{C}_{4} \mathrm{H}_{4} \mathrm{O}_{6} \text { и } \mathrm{H}_{2} \mathrm{C}_{4} \mathrm{H}_{4} \mathrm{O}_{6} \text { (тартратный) } \\
\mathrm{KH}_{2} \mathrm{PO}_{4} \text { и } \mathrm{Na}_{2} \mathrm{HPO}_{4} \text { (фосфатный) }\end{array}$ & $\begin{array}{l}{\left[\mathrm{Fe}(\mathrm{COO})_{4}(\mathrm{OH})_{4}\right]^{5-}} \\
{\left[\mathrm{Fe}\left(\mathrm{HPO}_{4}\right)_{4}\right]^{5-}}\end{array}$ & $\begin{array}{l}99.99 \\
99.99\end{array}$ \\
\hline $\mathrm{Cu}(\mathrm{II})$ & 4.0 & $\mathrm{~K}_{2} \mathrm{C}_{4} \mathrm{H}_{4} \mathrm{O}_{6}$ и $\mathrm{H}_{2} \mathrm{C}_{4} \mathrm{H}_{4} \mathrm{O}_{6}$ (тартратный) & {$\left[\mathrm{Cu}(\mathrm{COO})_{2}(\mathrm{OH})_{2}\right]^{2-}$} & 99.00 \\
\hline $\mathrm{Cd}(\mathrm{II})$ & 1.0 & HCl (1 М соляная кислота) & {$\left[\mathrm{Cd}\left(\mathrm{H}_{2} \mathrm{O}\right)_{6}\right]^{2+}$} & 96.83 \\
\hline $\mathrm{Ni}(\mathrm{II})$ & 7.0 & $\mathrm{H}_{2} \mathrm{O}$ (дист. вода) & {$\left[\mathrm{Ni}\left(\mathrm{H}_{2} \mathrm{O}\right)_{4}\right]^{2+}$} & 80.48 \\
\hline $\mathrm{Pb}(\mathrm{II})$ & 1.0 & $\mathrm{HCl}$ (1 М соляная кислота) & {$\left[\mathrm{PbCl}_{4}\right]^{2-}$} & 97.79 \\
\hline $\mathrm{Co}(\mathrm{II})$ & 6.8 & $\mathrm{KH}_{2} \mathrm{PO}_{4}$ и $\mathrm{Na}_{2} \mathrm{HPO}_{4}$ (фосфатный) & {$\left[\mathrm{Co}\left(\mathrm{H}_{2} \mathrm{O}\right)_{4}\right]^{2+}$} & 91.67 \\
\hline Mo(VI) & 4.0 & $\mathrm{~K}_{2} \mathrm{C}_{4} \mathrm{H}_{4} \mathrm{O}_{6}$ и $\mathrm{H}_{2} \mathrm{C}_{4} \mathrm{H}_{4} \mathrm{O}_{6}$ (тартратный) & $\begin{array}{l}\mathrm{MoO}_{4}^{2-} \\
{\left[\mathrm{Mo}_{6} \mathrm{O}_{21}\right]^{6-}} \\
{\left[\mathrm{Mo}_{7} \mathrm{O}_{24}\right]^{6-}}\end{array}$ & 98.55 \\
\hline
\end{tabular}

Таблица 2. Зависимость степени сорбции (\%) ионов металлов композитом СГ-ПАн с привитым 8-оксихинолином от рН среды. Условия эксперимента: статический режим, масса адсорбента 0.1 г, масса металла в исходном растворе 100 мКг, время адсорбции 24 ч

\begin{tabular}{c|c|c|c|c|c|c|c|c|c}
\hline \multirow{2}{*}{$\mathrm{pH}$} & \multicolumn{9}{c}{ Степень сорбции, \% } \\
\cline { 2 - 10 } & $\mathrm{Pb}^{2+}$ & $\mathrm{Cd}^{2+}$ & $\mathrm{Mo}^{6+}$ & $\mathrm{Al}^{3+}$ & $\mathrm{Zn}^{2+}$ & $\mathrm{Cu}^{2+}$ & $\mathrm{Fe}^{3+}$ & $\mathrm{Co}^{2+}$ & $\mathrm{Ni}^{2+}$ \\
\hline 1.0 & 97.79 & 96.83 & 89.78 & 87.64 & 0 & 98.63 & 66.00 & 42.55 & 15.15 \\
1.7 & 77.36 & - & 91.30 & 98.54 & 0 & 98.85 & - & - & 15.15 \\
4.0 & 78.84 & 52.03 & 98.55 & 0 & 0 & 99.00 & 99.99 & 55.81 & 41.87 \\
6.8 & 98.46 & 80.34 & 86.91 & 99.99 & 99.99 & 85.84 & 99.99 & 91.67 & 53.75 \\
7.0 & 90.71 & 85.59 & 94.00 & 97.06 & 97.20 & 91.58 & 60.00 & 77.9 & 80.48 \\
8.0 & 75.21 & 85.17 & 91.30 & 94.20 & 10.00 & 87.64 & 60.00 & 68.43 & 50.78 \\
9.1 & 85.11 & 84.92 & 81.85 & 95.79 & 75.00 & 91.13 & 89.90 & 97.6 & 38.9 \\
\hline
\end{tabular}

Полученные зависимости сорбции ионов переходных металлов от кислотности среды выгодно отличаются от зависимостей сорбции этих катионов поверхностью силикагеля с закрепленным 8-оксихинолином [14, 15] прежде всего высокой степенью извлечения высокотоксичных металлов в кислотной области $\mathrm{pH}$.

Результаты исследований кинетики сорбции ионов переходных металлов на поверхности СГ-ПАн с химически привитым 8-оксихинолином при оптимальных значениях кислотности среды показаны на рис. 1, 2. При этом наилучшие кинетические характеристики синтезированный адсорбент проявляет по отношению к высокоток- сичным ионам $\mathrm{Pb}$ (II) и $\mathrm{Cd}(\mathrm{II})$, максимально извлекая их на протяжении нескольких минут контакта (рис. 1, кривые 1, 2). Максимальное извлечение ионов меди(II) и молибдена(VI) происходит только через сутки контакта раствора с адсорбентом (табл. 1; рис. 1, кривые 3,4 ). Полученные данные могут косвенно свидетельствовать в пользу комплексообразующего механизма адсорбции, так как при ионообменном механизме твердофазное извлечение молибдат-ионов происходит практически мгновенно [8, 9].

Сравнение данных, приведенных в табл. 1 и на рис. 2, свидетельствует о том, что среди ионов подгруппы железа наилучшие кинетические по- 


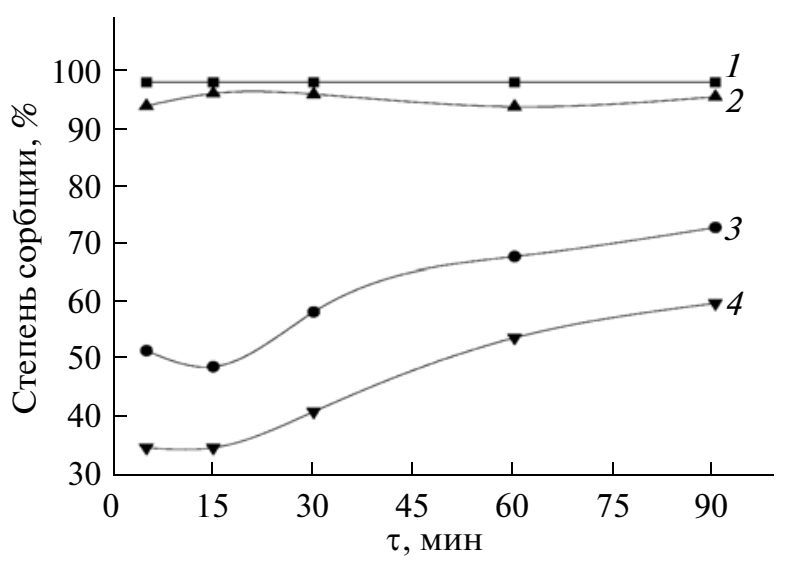

Рис. 1. Зависимость степени сорбции ионов токсичних металлов на поверхности СГ-ПАн с закрепленным 8-оксихинолином от времени контакта в статическом режиме: $1-\mathrm{Pb}(\mathrm{II}), \mathrm{pH} 1.0 ; 2-\mathrm{Cd}(\mathrm{II}), \mathrm{pH} 1.0$; $3-\mathrm{Mo}(\mathrm{VI}), \mathrm{pH} 4.0 ; 4-\mathrm{Cu}(\mathrm{II}), \mathrm{pH} 4.0$.

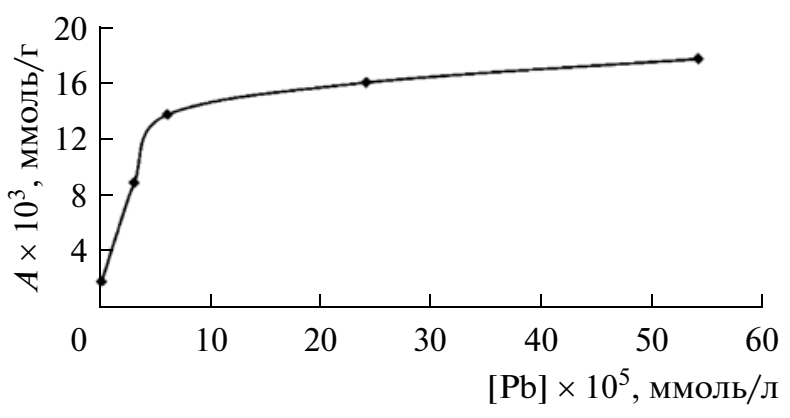

Рис. 3. Изотерма адсорбции $\mathrm{Pb}(\mathrm{II})$ на СГ-ПАн с закрепленным 8-оксихинолином. Условия эксперимента: масса адсорбента 0.1 г, объем растворов 25 мл, статический режим, время контакта 24 ч, рН 1.0.

казатели модифицированный оксином композит проявляет по отношению к ионам $\mathrm{Fe}(\mathrm{III})$, максимально извлекая их начиная с 90 мин контакта (рис. 2, кривая 1). Степень сорбции ионов $\mathrm{Ni}$ (II) и Co(II) постепенно возрастает со временем и достигает максимума только через сутки контакта раствора с адсорбентом (табл. 1; рис. 2, кривые 2, 3).

Возможный состав комплексов ионов переходных металлов с 8-оксихинолином, химически закрепленным на поверхности композита СГ-ПАн, оценивали путем определения степени сорбции этих ионов при различных начальных концентрациях в растворе, построения изотерм сорбции и расчета максимального значения сорбционной емкости полученного адсорбента по отношению к каждому иону.

Полученные изотермы сорбции $\mathrm{Cu}(\mathrm{II}), \mathrm{Cd}(\mathrm{II})$, $\mathrm{Pb}(\mathrm{II})$ (рис. 3), $\mathrm{Co}(\mathrm{II}), \mathrm{Ni}(\mathrm{II})$ и $\mathrm{Al}(\mathrm{III})$, согласно

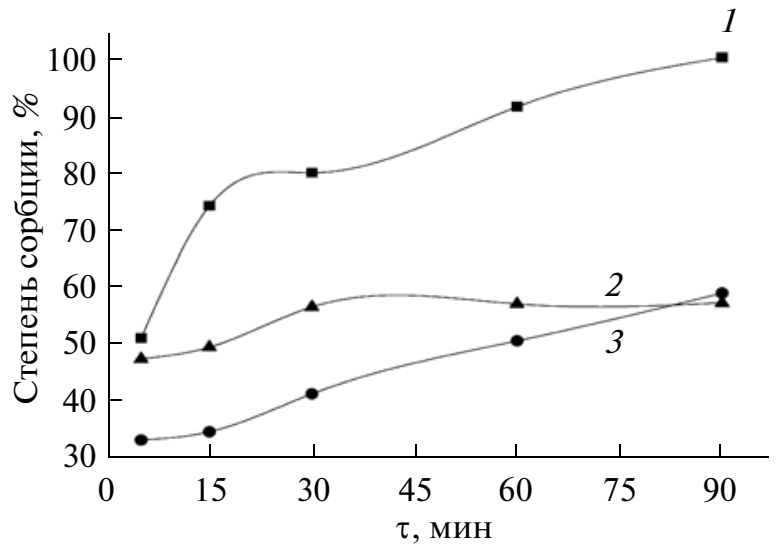

Рис. 2. Зависимость степени сорбции ионов металлов подгруппы железа на поверхности СГ-ПАн с закрепленным 8-оксихинолином от времени контакта в статическом режиме: 1 - Fe(III), $\mathrm{pH} 4.0 ; 2-\mathrm{Ni}(\mathrm{II}), \mathrm{pH}$ 7.0; $3-\mathrm{Co}(\mathrm{II}), \mathrm{pH} 6.8$.

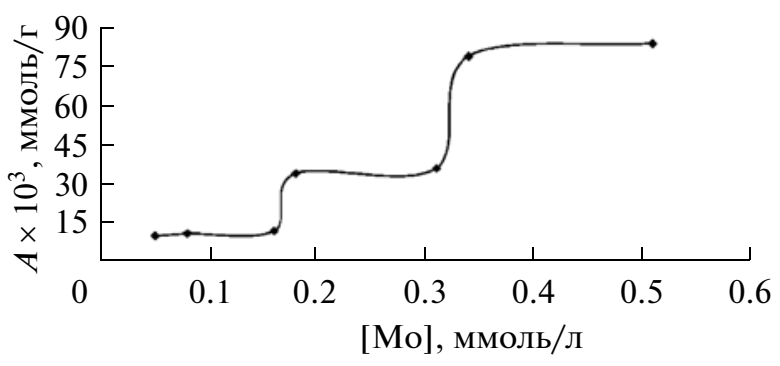

Рис. 4. Изотерма адсорбции Мо(VI) на СГ-ПАн с закрепленным 8-оксихинолином. Условия эксперимента: масса адсорбента 0.1 г, объем растворов 25 мл, статический режим, время контакта 24 ч, pH 4.0.

классификации Гильса, принадлежат к L2 типу [19]. Изотерма Мо(VI) имеет ступенчатый характер (рис. 4), что отражает, на наш взгляд, участие в комплексообразовании различных ионов Мо(VI) $\left(\mathrm{MoO}_{4}^{2-},\left[\mathrm{Mo}_{6} \mathrm{O}_{21}\right]^{6-},\left[\mathrm{Mo}_{7} \mathrm{O}_{24}\right]^{6-}\right)$, существующих в исходном растворе при оптимальных условиях сорбции (рН 4). Так, возрастание сорбционной емкости на последнем участке изотермы сопровождается увеличением сорбционной емкости по сравнению с первым изгибом изотермы в 7 раз (рис. 4), что может свидетельствовать о твердофазной экстракции при малых исходных концентрациях $\mathrm{Mo}(\mathrm{VI})$ в основном ионов $\mathrm{MoO}_{4}^{2-}$, а при дальнейшем увеличении исходной концентрации преимущественно в виде комплексных анионов.

Полученные изотермы позволили однозначно определить максимальную сорбционною емкость полученного адсорбента по отношению к иссле- 
Таблица 3. Сорбционная емкость исходного и модифицированного 8-оксихинолином композиционного материала силикагель-полианилин по отношению к ионам переходных металлов

\begin{tabular}{c|c|c|c|c|c}
\hline \multirow{2}{*}{ Ион } & \multirow{2}{*}{$\mathrm{pH}$} & \multicolumn{2}{c|}{$\begin{array}{c}\text { Сорбционная емкость исходного } \\
\text { композита СГ-ПАн }\end{array}$} & \multicolumn{2}{c}{$\begin{array}{c}\text { Сорбционная емкость СГ-ПАн } \\
\text { с закрепленным 8-оксихинолином }\end{array}$} \\
\cline { 3 - 6 } & & ммоль/г & мг/г & ммоль/г & мг/г \\
\hline $\mathrm{Al}(\mathrm{III})$ & 6.8 & - & - & 0.36 & 9.72 \\
$\mathrm{Co}(\mathrm{II})$ & 6.8 & 0.01 & 0.51 & 0.07 & 4.13 \\
$\mathrm{Mo}(\mathrm{VI})$ & 4.0 & 0.21 & 20 & 0.08 & 7.68 \\
$\mathrm{~Pb}(\mathrm{II})$ & 1.0 & 0.003 & 0.62 & 0.02 & 4.14 \\
$\mathrm{Cu}(\mathrm{II})$ & 4.0 & 0.03 & 1.92 & 0.03 & 1.80 \\
$\mathrm{Ni}(\mathrm{II})$ & 7.0 & 0.07 & 4.37 & 0.02 & 1.18 \\
\hline
\end{tabular}

дованным ионам (табл. 3). Как можно видеть из полученных данных, для $\mathrm{Al}(\mathrm{III}), \mathrm{Pb}(\mathrm{II}), \mathrm{Co}(\mathrm{II})$ сорбционная емкость синтезированного сорбента выше, чем у исходного композиционного материала. Для ионов $\mathrm{Cu}(\mathrm{II})$ величины сорбционной емкости данных адсорбентов практически совпадают, а для ионов $\mathrm{Ni}(\mathrm{II})$ и Мо(VI) наблюдается снижение сорбционной емкости. В случае ионов Mo(VI) это можно объяснить изменением механизма сорбции с ионообменного на комплексообразующий.

Сравнение полученных результатов с подобными для силикагеля, модифицированного 3-аминопропилтриэтоксисиланом, параформом и 8-оксихинолином $[14,15]$, показывает, что для ионов $\mathrm{Cu}$ (II) и $\mathrm{Ni}(\mathrm{II})$ по величинам сорбционной емкости полученные данные совпадают, но для ионов Со(II) сорбционная емкость модифицированного композита примерно в 2 раза ниже. Таким образом, композит СГ-ПАн с химически привитым 8-оксихинолином вполне можно использовать для твердофазного извлечения и концентрирования микроколичеств ионов $\mathrm{Pb}(\mathrm{II}), \mathrm{Cd}(\mathrm{II}), \mathrm{Cu}(\mathrm{II})$, $\mathrm{Ni}(\mathrm{II}), \mathrm{Co}(\mathrm{II}), \mathrm{Al}(\mathrm{III}), \mathrm{Fe}(\mathrm{III})$ и $\mathrm{Mo}(\mathrm{VI})$.

Для определения соотношения металл : 8-оксихинолин в разнолигандных комплексах на поверхности полученного адсорбента для всех исследованных ионов были построены изотермы (при оптимальных значениях рН и времени адсорбции для каждого из металлов) в координатах $C_{\mathrm{M}}^{\mathrm{K}} / C_{8 \text {-ох }}$ от $C_{\mathrm{M}}^{0} / C_{8 \text {-ох }}$, где $C_{\mathrm{M}}^{0}-$ исходная концентрация ионов металла в растворе, $C_{\mathrm{M}}^{\mathrm{K}}-$ концентрация ионов металла на поверхности, $C_{8-\mathrm{ox}}-$ содержание закрепленного на поверхности 8-оксихинолина. Пример такой изотермы для ионов $\mathrm{Cu}(\mathrm{II})$ показан на рис. 5. Как следует из рисунка, соотношение $C_{\mathrm{Cu}}^{\mathrm{K}}: C_{8 \text {-ох }}$ в области насыщения поверхности адсорбента металлом равняется $1: 1$, что соответствует следующему строению разнолигандных комплексов $\mathrm{Cu}(\mathrm{II})$ на поверхности при рН 4:

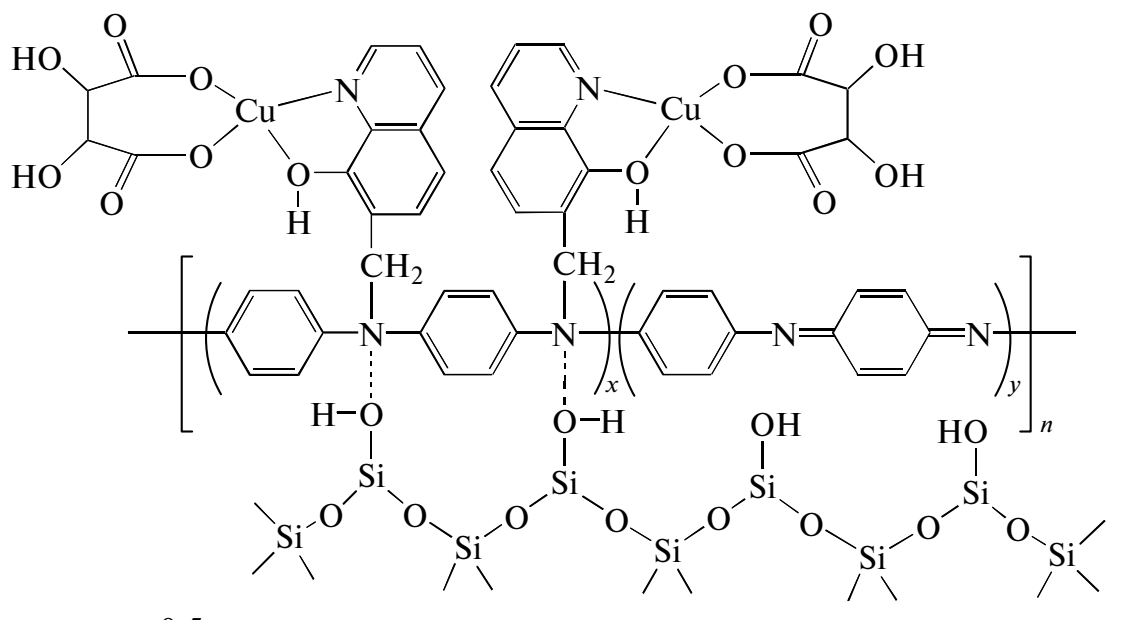

$x, y=0.5$ 


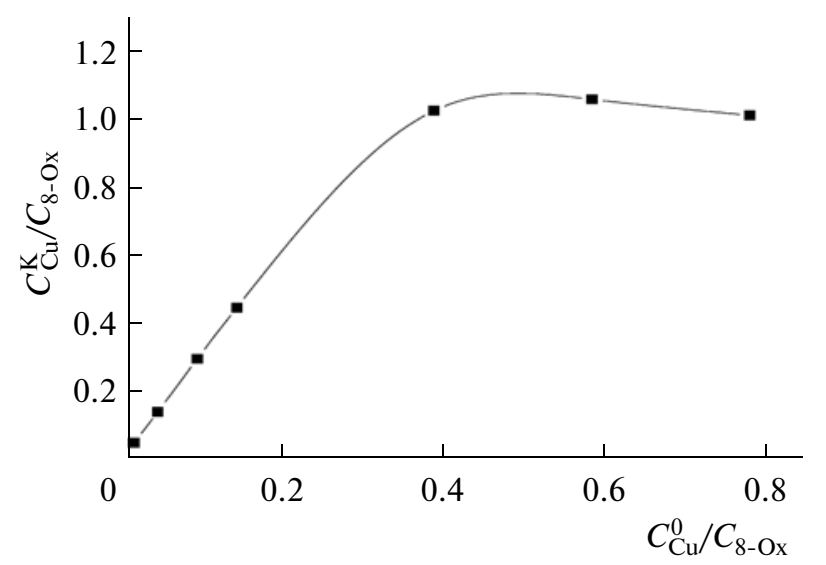

Рис. 5. Изотерма адсорбции $\mathrm{Cu}(\mathrm{II})$ на СГ-ПАн с закрепленным 8-оксихинолином. Условия эксперимента: масса адсорбента 0.1 г, объем растворов 25 мл, статический режим, время контакта 24 ч, рН 4.0.

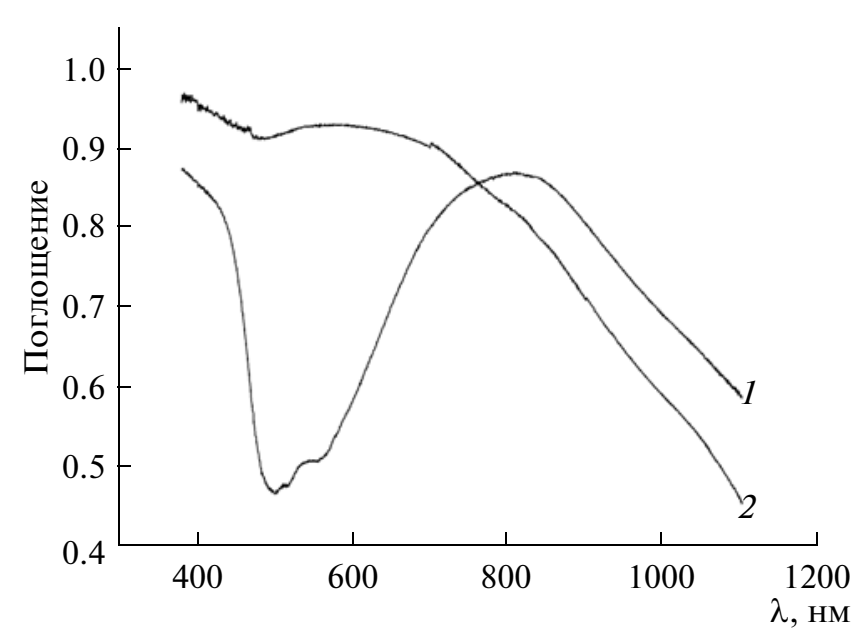

Рис. 6. Электронные спектры диффузного отражения СГ-ПАн с закрепленным 8-оксихинолином (1) и комплексов с Zn(II) на поверхности адсорбента (2).

Соотношение $C_{\mathrm{Mo}}^{\mathrm{K}}: C_{8 \text {-ох }}$ на горизонтальном участке изотермы составляет $1: 4$ и хорошо коррелирует с комплексообразующими свойствами ионов Мо(VI).

Для выяснения строения поверхностных комплексов металлов были исследованы ЭСДО образцов адсорбента, содержащих 100 мкг каждого из исследованных металлов. На рис. 6 показан пример ЭСДО для поверхностных комплексов с ионами Zn(II), пересчитанный на поглощение. Полученные ЭСДО для поверхностных комплексов с другими исследоваными металлами подобны данному. Как видно из рис. 6 , в спектре комплекса $\mathrm{Zn}(\mathrm{II})$ на поверхности модифицированного композита наблюдаются полосы поглощения в обла- сти 380-400 нм, болем интенсивные, чем у самого адсорбента, которые характерны для оксихинолятов переходных металлов [18]. В области 500700 нм имеется широкая полоса переноса заряда металл-лиганд. Поскольку у всех металлов эта полоса размыта, можно предположить, что на поверхности существуют наборы несколько отличных по строению разнолигандных комплексов, в состав которых входят молекулы 8-оксининолина, химически привитого к поверхности композита силикагель-полианилин.

Таким образом, с помощью реакции аминометилирования осуществлена ковалентная иммобилизация 8-оксихинолина на поверхности композиционного материала силикагель-полианилин, что подтверждено методами ИК-спектроскопии и термогравиметрии. Полученный адсорбент, в отличие от исходного композиционного материала, проявляет высокую сорбционную активность по отношению к микроколичествам ионов переходных металлов в кислой и слабокислой среде за счет своих комплексообразующих свойств. Синтезированный адсорбент имеет удовлетворительные кинетические характеристики и высокую сорбционную емкость по отношению к микроколичествам ионов переходных металлов, что делает композит СГ-ПАн с химически привитым 8оксихинолином перспективным для твердофазного извлечения и концентрирования микроколичеств ионов $\mathrm{Pb}(\mathrm{II}), \mathrm{Cd}(\mathrm{II}), \mathrm{Cu}(\mathrm{II}), \mathrm{Ni}(\mathrm{II})$, $\mathrm{Co}(\mathrm{II}), \mathrm{Al}(\mathrm{III}), \mathrm{Fe}(\mathrm{III})$ и $\mathrm{Mo}(\mathrm{VI})$ из водных растворов. Анализ изотерм адсорбции исследованных ионов переходных металлов свидетельствует о том, что соотношение $\mathrm{Cu}(\mathrm{II}): 8$-оксихинолин в комплексах на поверхности составляет $1: 1$, а для комплексов с Мо(VI) - $1: 4$. Исследование строения комплексов адсорбированных переходных металлов методом ЭСДО позволяет предположить, что на поверхности существуют наборы несколько отличных по строению разнолигандных комплексов, в состав которых входят молекулы 8оксихинолина, химически закрепленные на поверхности композита СГ-ПАн.

\section{СПИСОК ЛИТЕРАТУРЫ}

1. Bhadra S., Khastgir D., Singha N.K., Lee J.H. // Progr. Polym. Sci. 2009. V. 34. P. 783.

2. Lengalova A., Pavlinek V., Saha P. et al. // Physica. A. 2003. V. 321. № 3-4. P. 411.

3. Sotomayor P.T., Raimundo I.M., Zarbin A.J.G. et al. // Sensors Actuator. 2001. V. 74. P. 157.

4. Drelinkiewicz A., Stejskal J., Waksmundzka A., Sobczak J.W. // Synthetic Met. 2004. V. 140. P. 233.

5. Olad A., Naseri B. // Progr. Org. Coat. 2010. V. 67. P. 233. 
6. Minjia H., Chao T., Qunfang Z., Guibin J. // J. Chromatogr. A. 2004. V. 50. P. 257.

7. Яновська Е.С., Будняк T.M. // Екологія міст та рекреаційних зон: Тез. доповідей та виступів Всеукр. науково-практ. конф. Одеса, 2010. С. 413.

8. Будняк Т.М., Яновська Е.С., Тьортих В.А., Кичкирук О.Ю. // Вопр. химии и хим. технологии. 2010. № 5. C. 43 .

9. Будняк Т.М., Яновська Е.С., Тьортих В.А., Вознюк В.І. // Доповіді НАН України. 2011. № 3. С. 141.

10. Яновська Е.С., Рябченко К.В., Кичкирук О.Ю., Тьорmих B.A. // Тез. доповідей XVIII Укр. конф. з не орган. хімії за участю закордонних вчених. Харків, 2011. C. 306.

11. Tertykh V.A., Yanishpolskii V.V., Panova O.Yu. // J. Therm. Anal. Calorim. 2000. V. 62. № 2. P. 545.
12. Вознюк В.I, Тьортих В.А., Янишпольський В.В., Оніщенко Ю.К. // Хімія, фізика та технологія поверхні. 2003. Вип. 9. С. 140.

13. Aboutanos V., Barisci J.N., Kane-Maguire L.A.P., Wallace G.G. // Synthetic Met. 1999. V. 106. P. 89.

14. Glushchenko O.V., Yanovska E.S., Kichkiruk O.Yu., Tertykh V.A. // Functional Mater. 2006. V. 13. № 2. P. 265.

15. Yanovska E.S., Glushchenko O.V., Karmanov V.I. et al. // Adsorpt. Sci. Technol. 2006. V. 24. № 3. P. 229.

16. Марченко 3. Фотометрическое определение элементов. М.: Мир, 1971. 502 с.

17. Наканиси K. Инфракрасные спектры и строение органических соединений. М.: Мир, 1965. 216 с.

18. Giles C.H., MacEwan T.H., Nakhwa S.N., Smith D. // J. Chem. Soc. 1960. V. 4. P. 3973.

19. Ливер Э. Электронная спектроскопия неорганических соединений. В 2-х ч. Ч. 2. М.: Мир, 1987. 445 с. 